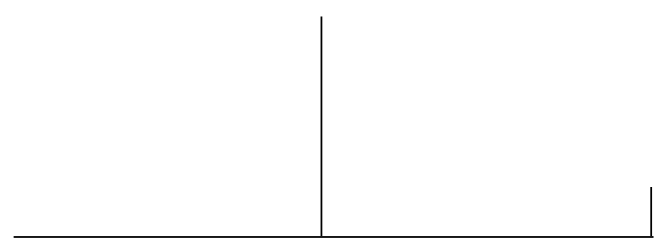

Rev. Latinoam. Psicopat. Fund., São Paulo, v. 15, n. 4, p. 825-837, dezembro 2012

\title{
O psicanalista no tratamento $\overline{\text { da dor }}$
}

Sueli Pinto Minatti

A dor se manifesta como mal-estar do corpo e no corpo, e tende a ser encaminhada para tratamento médico. $O$ objetivo deste trabalho é analisar a queixa dolorosa do ponto de vista do tratamento psicanalítico, retomando algumas acepções relacionadas ao tratamento da dor, encontradas na obra de Freud. Partimos da experiência no trabalho em hospital pediátrico, utilizando a análise do atendimento de pacientes com queixas de dor para definir e situar a dor no campo da psicanálise, e distingui-la do campo da medicina. No texto, pode-se acompanhar a dor como signo de sofrimento $e$ diversas formas de abordá-la tanto pelo sujeito que a porta quanto pelas instituições que propõem seu cuidado.

Palavras-chave: Dor, psicanálise, pediatria, sofrimento 
Um homem com uma dor,

É muito mais elegante

Caminha assim de lado

Como se chegando atrasado

Andasse mais adiante

Carrega o peso da dor

Como se portasse medalhas Uma coroa, um milhão de dólares

Ou coisa que os valha Ópios, édens, analgésicos Não me toquem nessa dor

Ela é tudo que me sobra Sofrer vai ser a minha última obra.

(Zélia Duncan, Dor elegante)

Gabriela chegou para atendimento psicanalítico aos oito anos, encaminhada pela especialidade pediátrica de dor e cuidados paliativos, com diagnóstico de fibromialgia. ${ }^{1}$ A mãe relata dores na filha desde os dois anos de idade. Quando chegou, submetia-se a tratamentos frequentes em outras especialidades, tais como reumatologia e acupuntura, além de submeter-se a inúmeras internações, ocasionadas sempre por dor.

${ }^{1}$ Fibromialgia (FM) é uma síndrome reumática não articular, de origem desconhecida, caracterizada por dor musculo esquelética difusa e crônica, e presença de múltiplas regiões dolorosas, denominadas tender points, especialmente no esqueleto axial. (1) Dentre os sintomas frequentemente associados à síndrome, podem estar presentes fadiga, distúrbios do sono, rigidez matinal, ansiedade e depressão (2) In Cacalcante et al. A prevalência de fibromialgia: uma revisão de literatura. Recuperado em 12 de agosto de 2011 do <http://www.scielo.br/pdf/rbr/v46n1/29386.pdf>. 
Laura chegou para atendimento aos 14 anos. Apresentava enxaqueca vinte e quatro horas por dia, como ela mesma dizia. À época, frequentava dez especialidades pediátricas no hospital, lugar em que passava mais tempo do que em qualquer outro, incluindo sua casa e a escola.

Enzo veio para atendimento aos cinco anos, com dores nas pernas, que já o impediram de andar algumas vezes. Diagnóstico médico não fechado; ademais, queixa de agressividade.

Gabriela, Laura e Enzo são três das muitas crianças e adolescentes que chegam ao psicanalista com a queixa de dor.

Como receber e encaminhar esses atendimentos? Qual estatuto dar à dor no tratamento psicanalítico com crianças?

$\mathrm{Na}$ instituição hospitalar em que trabalho, a especialidade que cuida da dor - Unidade de Dor e Cuidados Paliativos - é a mais recente, dentre as demais dezenas de especialidades pediátricas. E, também, é pioneira no Brasil. Para o campo médico, a dor é considerada o sintoma mais subjetivo, uma vez que sua visibilidade e mensuração dependem do relato do paciente, na medida em que, na maior parte dos casos, não há exame de imagem ou de laboratório em que essa queixa possa ser constatada. São utilizadas escalas diversas para que o paciente possa comunicar ao médico seu grau de dor, que vão de desenhos de rostos alegres a tristes, para as crianças menores, não alfabetizadas, a escalas de números para os demais. Nessa tentativa de transmissão, acontecem situações enigmáticas para a equipe médica quando, por exemplo, nas escalas de mensuração que vão de um a dez, a criança ou o adolescente diz ter $d o r d e z$, mas demonstra semblante tranquilo, movimentos ligeiros e nenhum sinal aparente que o poderia definir como paciente doloroso. Por outro lado, a equipe tranquiliza-se quando, juntamente com a queixa dolorosa, aparece um edema, o que por sua visibilidade justifica que há algo. A valorização do edema pela equipe pode ter efeitos de certificação do sofrimento, apresentado como dor. Encontra-se resposta a esta forma de tomar a queixa do paciente, pelo próprio paciente, quando este se apresenta pelo edema diante da pergunta: "O que é que você tem?". Sem o edema, ou sinal visível, a equipe médica lida com algo subjetivo, ponto de angústia, do qual se tenta distanciar, encaminhando-o a outras especialidades, ou duvidando da dor, por exemplo.

Essa forma como a dor é tomada pelo médico torna-se compreensível quando consideramos a medicina como o campo científico da objetividade e da generalização, em que importa o observável, o mensurável e o registrável, havendo à disposição grande variedade de medicamentos e modalidades de procedimentos, que tentam dar conta dos variados tipos e intensidades de dor, com o objetivo de eliminá-la. Verifica-se, no entanto, neste campo do tratamento da dor, grande incidência de medicamentos que não provocam, em todos os pacientes, os efeitos 
esperados. Assim como pacientes que não seguem o tratamento de acordo com a prescrição médica. Muitos desses casos são encaminhados ao psicanalista que faz parte da equipe de dor, o que sinaliza o lugar em que este profissional costuma ser colocado pela equipe, ou seja, como aliado do tratamento médico.

Acerca do estudo da dor, na psicanálise, como afirma Berlinck (1999) há numerosas referências e poucos trabalhos que a tratam sistematicamente. Entre essas possibilidades, escolhemos analisar nossa experiência clínica a partir do resgate de algumas acepções freudianas e de alguns de seus comentadores recentes, como acompanharemos a seguir.

Sobre as referências em Freud, já as encontramos nos textos pré-psicanalíticos. No texto "Estudos sobre a histeria" (1893), em que se discutem cinco casos clínicos, três apresentam referências à dor. Um destes é o caso da srta. Elisabeth Von R., de 24 anos, atendida por Freud no outono de 1892. Ela foi encaminhada a Freud por um médico seu conhecido, ressaltando que a examinasse, dado que "vinha sofrendo há mais de dois anos de dores nas pernas e que tinha dificuldades em andar" (p. 161). Freud observou que "o distúrbio se desenvolvera gradativamente durante os dois anos anteriores e variava bastante em intensidade" (p. 162). Outra observação nos faz pensar em algumas das formas atuais de apresentação da dor encontradas pelos médicos:

(...) quando se pressionava ou beliscava a pele e os músculos hiperalgésicos de suas pernas, seu rosto assumia uma expressão peculiar, que era antes de prazer do que de dor. Ela gritava mais e eu não podia deixar de pensar que era como se ela estivesse tendo uma voluptuosa sensação de cócega - o rosto enrubescia, ela jogava a cabeça para trás e fechava os olhos, e seu corpo se dobrava para trás. (...) Sua expressão facial não se ajustava à dor evidentemente provocada pela beliscadura dos músculos e da pele; provavelmente se harmonizava mais com o tema dos pensamentos que jaziam ocultos por trás da dor e que eram despertados nela pela estimulação das partes do corpo associadas com esses pensamentos. (p. 163)

Nessa época, Freud estava interessado na histeria, que ele distinguiu de outras patologias pela conversão, e a dor aparece como uma das manifestações conversivas. Ou seja, ele extrai a dor dentre os fenômenos histéricos para situá-la, posteriormente, como constituinte do corpo (Freud, 1914).

Ao examinarmos o total da obra de Freud, encontramos inúmeras referências sobre a dor, que vão de representações aflitivas, junto com a vergonha e a autocensura (1893), diferentes formas de expressar a dor em crianças e adultos (1905a) a considerações sobre a produção ou desaparecimento da dor, em relação à atenção que se dê a ela (1905b). Freud alerta, mais de uma vez, sobre a natureza imperativa da dor (1905a e 1915); fala da falta de interesse pelo mundo 
provocado por dores lancinantes (1914); faz análises a respeito de infligir dor em si próprio e no outro (1915); fala da dor da perda (1926), assim como outros sentidos da dor, como a da desonra, sobrepondo a dor física no caso de algumas agressões e abusos (1918). Fala, além disso, da dor como algo a que o paciente resiste em se livrar (1916/1917), como se pode verificar abaixo:

Pensem apenas nisto: $\mathrm{O}$ paciente, que tanto sofre com os seus sintomas e tanto sofrimento causa àqueles que convivem com ele, que está disposto a enfrentar tantos sacrifícios em tempo, dinheiro, esforço e autodisciplina, a fim de se libertar desses sintomas - temos de acreditar que esse mesmo paciente empreende uma luta no interesse da sua doença, contra a pessoa que o está ajudando. Como deve parecer improvável esta afirmação! E, no entanto, é verdadeira; e quando sua improbabilidade nos é apontada, podemos somente responder que essa situação também tem analogias. Uma pessoa que vai ao dentista, por causa de uma dor de dente insuportável, assim mesmo procurará afastar o dentista quando este se aproxima do dente doente, com um boticão. (p. 293-294)

Ainda em "O ego e o id" (1923), Freud fala que

(...) a dor parece desempenhar um papel no processo, e a maneira pela qual obtemos novo conhecimento de nossos órgãos durante as doenças dolorosas constitui talvez um modelo da maneira pela qual em geral chegamos à ideia de nosso corpo. (p. 39)

Estas são algumas acepções que nos ajudam a refletir sobre os casos trazidos para ilustração deste texto e que nos fazem pensar que a dor se manifesta no corpo, e pelo corpo, e que a ideia de corpo inclui a dor. Ela aparece, principalmente, como uma expressão da linguagem que evoca valores e posições do sujeito em relação aos objetos do mundo - agora falando da teoria psicanalítica de acordo com Lacan, psicanalista que releu Freud e trouxe novos aportes teóricos.

Então, interessa-nos a relação que o sujeito - sujeito do inconsciente - estabelece com a dor. Entendemos que as manifestações da dor são singulares, tendendo a ser surpreendentes e fugindo a padrões predeterminados. O sujeito doloroso encaminhado pelos médicos pode, por exemplo, não falar da dor quando se consulta com o psicanalista, mas pode, sim, enveredar por outros meandros, uma vez que a dor não tem fundamento unicamente no organismo, mas na concepção de corpo que cada sujeito apresenta e no sentido que vai dando aos eventos do mundo e no mundo. E, ainda que não fale da dor, ou fale da forma como ela se apresenta na sua concepção, seu percurso pela fala mostra efeitos sobre a dor.

Ademais, as diferentes formas de relação com a dor sinalizam formas peculiares de relação com o corpo, o que por sua vez sinaliza o campo de trabalho subjetivo. Como, por exemplo, uma outra criança que tinha pouco contato visual 
com os objetos do mundo, linguagem bastante empobrecida para sua idade e falta de reconhecimento - falta de nomeação e manejo-das partes do corpo. Esta criança entregava seu corpo como um objeto quase inexistente; sem escolhas, por exemplo, do que gostava de comer, de brincar, com quem queria se relacionar, sem se deter com discriminação, interesse e curiosidade pelos objetos ao redor. A olhos vistos, apresentava um corpo desorganizado e desconjuntado, esbarrando, tropeçando, passando por cima de pessoas e objetos, sem se deter a nada; ou, melhor falando, detendo-se precariamente. Os órgãos dos sentidos que a ligavam ao mundo pareciam embotados. O curioso, a respeito da dor nessa criança, é a ausência de sensações dolorosas de qualquer espécie, o que a colocava em perigo, ainda que não houvesse justificativa orgânica para tal. Isto nos faz pensar, por um lado, na ausência de dor em um sujeito bastante desapossado de seu corpo, aos nove anos, exigindo vigilância e direção de adultos em tarefas simples como vestir-se ou utilizar os objetos - de utilidade doméstica, ou lúdica, por exemplo - à sua disposição. Por outro lado, isso nos detém no aspecto da dor como elemento necessário, tanto na sinalização de perigo e de tradução para limites quanto na representação do mal-estar e da forma de dizer do sofrimento. Um aliado, portanto.

Freud (1926) aproxima a dor da angústia, e a define como manifestação do humano, como um sinal da falta. Angústia retomada por Lacan, como "o que não engana" (1962/1963, p. 131). Nasio (1997) distingue, na leitura de Freud, dor como manifestação da perda e angústia como ameaça de perda. Berlinck (1999), ao deter-se numa carta de Freud a Pfister, chega à dor "que se manifesta na catástrofe e na perda desse mesmo objeto e a angústia, que ocorre como um sinal de persistência da catástrofe [e que] constituem, na ótica freudiana, o corpo humano, que está permanentemente sob ameaça (...)" (p. 18).

Diante da ameaça o sujeito busca garantias, via pela qual um diagnóstico pode ser tomado, e pode entrar num lugar de verdade ou asseguramento que nunca são suficientes, acionando, dessa forma, outras buscas e provocando deambulações por diversas especialidades médicas, só para citar alguns destinos.

Sabemos, então, que não para todos, ou não durante todo o tempo, um diagnóstico ou um nome oferece garantias. Os escapes provocam novas deambulações, uma vez que a angústia permanece.

A angústia pode ser traduzida como um mal-estar geral, ou difuso, que pode paralisar ou acelerar o acometido, mas pode, também, manifestar-se próxima à forma da dor, e até mesmo confundir-se com ela, localizando-se numa parte do corpo. Como o caso de Ruth que, desde os três anos, época do nascimento de sua irmã, vai sendo puxada pela mão da mãe pelos corredores e ambulatórios do hospital, em busca de tratamento para a outra filha recém-nascida com problemas congênitos severos. Circula com ambas pelas diversas especialidades 
pediátricas, nas quais todo investimento e atenção eram colocados neste bebê. Sobre Ruth, a mãe se lembra de que corria sem rumo e de que chorava incessantemente, aparentemente sem motivo e sem que a mãe se detivesse a pesquisá-lo. Até que um dói aqui, dito pela menina, deu-lhe lugar nessa mesma instituição. Agora, a mãe se ocupa de duas filhas. Aos sete anos, Ruth chegou ao psicanalista, com o diagnóstico médico de fibromialgia.

Retomando os casos que iniciaram este texto, também Laura se queixava de dor no peito, de dificuldades para respirar e de paralisações diante de situações sociais. Para a mãe de Gabriela, ${ }^{2}$ havia uma pressão e uma dor no peito, além de muita fúria, que antes a levava a praticar atos socialmente reprováveis, tais como, evadir-se da cena familiar ou da cena social mais ampla. Na medida em que o sujeito falava, percorrendo pela via significante o seu desejo, a angústia poderia ser modulada. "Ali, alguma outra coisa quer se realizar - algo que aparece como intencional, certamente, mas de uma estranha temporalidade. O que se produz nessa hiância, no sentido pleno do termo produzir-se, se apresenta como um achado. É assim, de começo, que a exploração freudiana encontra o que se passa no inconsciente" (Lacan, 1964, p. 30; grifos do autor).

Ademais, ia aparecendo uma continuidade e uma perseverança em querer saber, tendo, como efeitos, adequações sociais mais interessantes, como nos diz a mãe de Gabriela: Eu ia enlouquecer lá fora [na sala de espera do ambulatório], mas teria dado a maior confusão e o tratamento da minha filha seria posto em risco, então esperei vir aqui para falar disso. É importante marcar que, anteriormente, havia enlouquecido nos mais variados lugares com prejuízos de várias espécies, tais como dificuldades em manter-se num emprego.

Caminhando por estas acepções teóricas, selecionamos a aproximação com a angústia e a resistência em livrar-se da dor, além desta como imperativo, para dizer que a dor aparece como forma de apresentar-se ao outro e pedir-lhe atenção ou reconhecimento, quando é possível este pedido. Ainda, quando os gritos ou os desarvoramentos são ouvidos por outros, quais sejam, pais ou cuidadores, professores, familiares, vizinhos, denunciadores, que tentam lhes dar sentido, ou tentam colocar-lhes diante de um especialista, para uma nomeação.

A dor clama por um nome. O psicanalista vai permitir que o sujeito resgate seu próprio sentido. Sentido como "uma ordem que surge" (Lacan, 1954/1955,

${ }^{2}$ É importante marcar que na clínica com crianças, os pais ou os cuidadores estão incluídos porque as trazem. Nesta clínica há um vasto percurso sobre como considerar os acompanhantes, inserindo-os, ou não, no tratamento. Escolhas que trazem efeitos ao tratamento, como nos aponta Faria (2004). Em nossos casos, sob esta perspectiva, podemos dizer que na maior parte das vezes era atendido um ou ambos os genitores. 
p. 292). Portanto, diferentemente do campo médico, nós, psicanalistas, pedimos àquele que se apresenta e/ou também àquele que o traz, no caso de atendimento de criança, fale. Esse é nosso objetivo: que apareça o sujeito por aquilo que diz.

Laura era invadida pela dor vinte e quatro horas por dia. Mas, em algum momento, ela se lembrou de que não sentia dor enquanto via novela. Não é curioso? Geralmente, sua consulta começava com estou com dor de cabeça... Mas sua narrativa perambulava por outros âmbitos que ia definindo sua posição frente ao social: a partir da família, que ela tomava como excessivamente exigente; os médicos, a quem tentava corresponder fielmente, cumprindo à risca os tratamentos; os colegas na escola, onde ela tirava os primeiros lugares, tendo, no entanto, dificuldades de relacionamento, se sentindo isolada.

Laura ficou em tratamento psicanalítico durante três anos. Neste tempo, foi tendo alta de algumas das dez especialidades médicas que frequentava. Ficaram as duas últimas: a especialidade de dor e o psicanalista, das quais ela se deu alta. A este último, resumidamente, trouxe várias justificativas: estou trabalhando, descobri que sou alegre, meus clientes gostam muito de mim, entrei na faculdade, não preciso mais do hospital. Ao anunciar alta ao médico, este perguntou: "E a dor de cabeça?" Ela respondeu: Ainda dói, mas posso levar. À medida que suas dificuldades ganharam nome, ela pôde transitar socialmente, levando e manejando seu mal-estar, que anteriormente encontrava uma expressão empobrecida pela via da nominação dolorosa, que a aprisionava.

Gabriela era trazida pela mãe, que a empurrava muitas vezes para dentro da sala de atendimento. A criança não apresentava queixas, entrando para mostrar a bolsa nova ou para dizer que tirou dez em matemática. Ditos, em geral, encomendados pela mãe. O primeiro pedido desta criança foi: não quero vir à psicóloga. Pedido ouvido. A mãe ficou; queria falar sobretudo de suas dificuldades com os filhos, evidenciando esta filha que lhe direcionava maciças demandas de amor. Esta mãe foi formulando uma questão que girava em torno de como ser mãe viva, uma vez que tinha um modelo de "mãe morta" que a colocava em situações difíceis, principalmente diante dos filhos. A construção deste papel permitiu acolher a angústia da filha, cujas dores foram se espaçando. A princípio, diante das dores, a mãe corria com ela ao hospital para que fizessem algo, ficando ambas furiosas diante do dito frequente ela não tem nada, uma vez que seu mal-estar era nomeado como dor física, que não aparecia pelos exames, e que ali não podia ser dito. Algo estava calado, enquanto a dor gritava. Posteriormente, pôde dar continência e direção ao sofrimento da filha quando ocorriam episódios dolorosos, construindo com ela possibilidades e impossibilidades diante da dor, definindo o arsenal medicamentoso disponibilizado pelos médicos, e delimitando o tempo de espera para efeito de cada medicamento. Portanto, do ponto de vista do tratamento médico houve maior adesão, dado que os cuidados se estendiam também a este. 


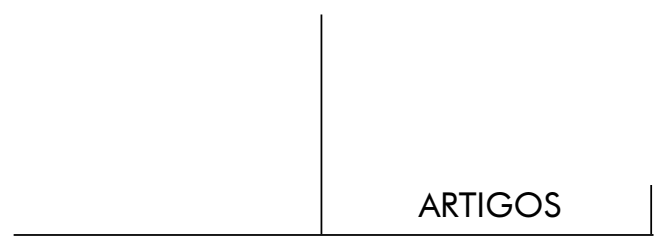

Paralelamente, dava-se conta das capacidades e da importância da participação da filha nos afazeres domésticos, antes poupados a esta "filha mimada", como a chamava, enquanto eram compartilhados pelos demais filhos. Ações cuidadosas foram dando outro lugar a Gabriela, que de várias formas demandava desta mãe, pedindo-lhe argumentos antes calados. A criança teve alta das especialidades no hospital; algum tempo depois, a mãe anunciou alta à psicanalista.

Para finalizar, podemos dizer que até o ponto em que acompanhamos Laura e Gabriela, as meninas não deixaram de ter dor, mas não eram mais dominadas por ela, porque a dor deixou de ser apenas mensagem colada ao corpo à espera de ser lida (Lacan, 1954/1955). Assim, deixou de ser apenas um signo reconhecível institucionalmente de seu sofrimento, como um aprisionamento, passando a ter um sentido e a ser parte da via significante do sujeito. Laura, anteriormente dominada pela dor, sem se dar conta, agora a leva, tornando-se seu agente. E Gabriela conta com os cuidados e a continência da mãe que, colocando-lhe limites, permitiu uma ordem de diferenças. Gabriela evocou não querer vir à psicóloga e ampliou seu ambiente social para além da mãe.

Podemos dizer que a dor é uma forma de sofrimento, e não queremos abatê-lo, porque sabemos que é inerente ao humano e só pode ser manifestado a partir do momento em que o sujeito fala.

Humanidade é ser e estar numa diferença que se constitui absoluta e que se traduz numa ávida e incansável busca de sentido. A lida com o simbólico imprime este absoluto da diferença, já que para os homens este modo de existência está posto "em seu sentido pleno e sua extensão máxima". (Garcia-Roza apud Paladino, 1999, p. 85, grifos do autor)

O sujeito, dessa forma, aparece pela fala na posição que toma em relação a seu universo.

Ademais, não queremos eliminar a dor, porque sabemos que ela - como outros signos apresentados no corpo e pelo corpo - é expressão que não conta com outras formas de representação. Esta falta de representação, que indica uma área de desconhecimento, pode ser recoberta por meio da fala e da ampliação de sentido que ela proporciona. Pela intervenção psicanalítica, a fala se desdobra em perguntas, questões e pedidos, meios pelos quais o sujeito se coloca como agente, subtraindo-o da função simplificada de portador do acometimento.

Enzo está em atendimento. Junto com a dor apresenta agressividade e isolamento na escola, comportamentos encontrados com frequência nos pacientes dolorosos. Enzo tem uma mãe com "muita pena" do filho, por suas internações e os vários exames invasivos a que já se submeteu. Esta situação a deixa confusa sobre colocar-lhe limites, como ela mesma diz, modo muito frequente de agir de pais ou de cuidadores de crianças submetidas a inúmeros tratamentos. 
Perguntamos: a dor causa os problemas sociais, ou vice-versa? E o que vamos encontrando, não está ali onde aparece a queixa, mas lá onde se situa o sujeito.

\section{Referências}

Berlinck, M. T. (1999). A dor. In M. T. Berlinck (Org.). Dor. São Paulo: Escuta.

Faria, M. R. (2004). As entrevistas preliminares aos tratamentos com crianças. Acheronta (Online), 20, 35-48.

Freud, S. (1996). Estudos sobre a histeria. In Edição Standard Brasileira das Obras Psicológicas Completas de Sigmund Freud (Vol. II). Rio de Janeiro: Imago. (Trabalho original publicado em 1893/1895)

Freud, S. (1996). A etiologia da histeria. In Edição Standard Brasileira das Obras Psicológicas Completas de Sigmund Freud (Vol. III). Rio de Janeiro: Imago. (Trabalho original publicado em 1896)

Freud, S. (1996). Três ensaios sobre a teoria da sexualidade. In Edição Standard Brasileira das Obras Psicológicas Completas de Sigmund Freud (Vol. VII). Rio de Janeiro: Imago. (Trabalho original publicado em 1905a)

Freud, S. (1996). Tratamento psíquico (ou anímico). In Edição Standard Brasileira das Obras Psicológicas Completas de Sigmund Freud (Vol. VII). Rio de Janeiro: Imago. (Trabalho original publicado em 1905b)

Freud, S. (1996). Sobre o narcisismo: uma introdução. In Edição Standard Brasileira das Obras Psicológicas Completas de Sigmund Freud (Vol. XIV). Rio de Janeiro: Imago. (Trabalho original publicado em 1914)

Freud, S. (1996). Conferências introdutórias sobre psicanálise - Resistência e Repressão (XIX). In Edição Standard Brasileira das Obras Psicológicas Completas de Sigmund Freud (Vol. XVI). Rio de Janeiro: Imago. (Trabalho original publicado em 1916/1917)

Freud, S. (1996). O tabu da virgindade (Contribuições à psicologia do amor III). In Edição Standard Brasileira das Obras Psicológicas Completas de Sigmund Freud (Vol. XI). Rio de Janeiro: Imago. (Trabalho original publicado em 1918)

Freud, S. (1996). O ego e o id. In Edição Standard Brasileira das Obras Psicológicas Completas de Sigmund Freud (Vol. XIX). Rio de Janeiro: Imago. (Trabalho original publicado em 1923)

Freud, S. (1996). Inibições, sintoma e ansiedade. In Edição Standard Brasileira das Rev. Latinoam. Psicopat. Fund., São Paulo, v. 15, n. 4, p. 825-837, dezembro 2012 


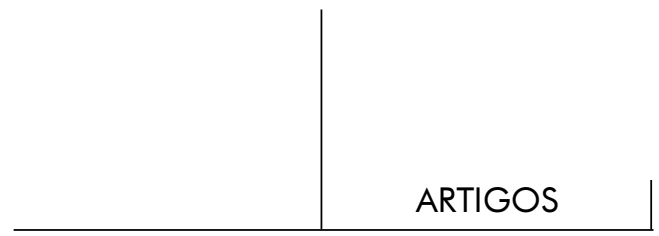

Obras Psicológicas Completas de Sigmund Freud (Vol. XX). Rio de Janeiro: Imago. (Trabalho original publicado em 1926)

Lacan, J. (1997). O seminário. Livro 2. O Eu na teoria de Freud e na técnica da psicanálise. Rio de Janeiro: Jorge Zahar. (Trabalho original publicado em 1954-1955)

Lacan, J. (2004). O seminário. Livro 10. A angústia. Rio de Janeiro: Jorge Zahar. (Trabalho original publicado em 1962-1963)

Lacan, J. (1996). O seminário. Livro 11. Os quatro conceitos fundamentais da psicanálise. Rio de Janeiro: Jorge Zahar. (Trabalho original publicado em 1964)

Nasio, J. D. (1997). O livro da dor e do amor. Rio de Janeiro: Jorge Zahar.

Paladino, R. (1999). Palavras da dor. In M. T. Berlinck (Org.). Dor. São Paulo: Escuta.

\section{Resumos}

(The psychoanalyst in the treatment of pain)

Pain is expressed can be described as physical discomfort and is usually treated medically. In this article we analyze complaints of pain from a psychoanalytic perspective, taking into account several Freudian concepts. We base the article on experiences in a pediatric hospital, related to the treatment of patients with complaints of pain, in order to define and situate pain in the psychoanalytic field and distinguish it from the field of medicine. In the text, pain can be seen as a sign of suffering, and there are various ways to treat it, both from the point of view of the person who feels it and from that of the institutions that propose to treat it.

Key words: Pain, psychoanalysis, pediatrician, suffering

(Le psychanalyste et le traitement de la douleur)

La douleur se manifeste comme mal physique et par le physique et on a tendance à recourir au traitement médical pour s'en affranchir. L'objectif de ce travail est d'analyser la plainte de la douleur du point de vue du traitement psychanalytique en reprenant quelques acceptions sur le traitement de la douleur dans l'œuvre de Freud. Nous prenons comme point de départ le travail dans un hôpital pédiatrique et en analysons les plaintes de douleur pour définir et situer la douleur au domaine de la psychanalyse et la distinguer du domaine de la médicine. La douleur peut donc être interprétée comme signe de souffrance et nous disposons de plusieurs façons de la traiter, non seulement par le sujet, mais aussi par les institutions qui en prennent compte.

Mots clés: Douleur, psychanalyse, pédiatrie, souffrance 
(El psicoanalista en el tratamiento del dolor)

El dolor se manifiesta como malestar del cuerpo y en el cuerpo y, tiende a ser derivado para un tratamiento médico. El objetivo de este trabajo es analizar la queja de dolor desde el punto de vista del tratamiento psicoanalítico, retomando algunos conceptos referidos al tratamiento del dolor presentes en la obra de Freud. Partimos de la experiencia del trabajo en hospital pediátrico, usando el análisis del tratamiento a pacientes que se quejan de dolor para definir y situar el dolor en el campo del psicoanálisis, distinguiéndolo del campo de la medicina. En el texto se puede acompañar el entendimiento del dolor como una señal de sufrimiento y las diversas formas de abordarlo, tanto por el sujeto que lo sufre como por las instituciones que proponen su cuidado.

Palabras clave: Dolor, psicoanalisis, pediatría, sufrimiento.

(Der Psychoanalyst bei der Schmerzbehandlung)

Der Schmerz äußert sich als Unbehagen des Körpers im Körper und wird, in der Regel, ärztlich behandelt. Ziel dieser Arbeit ist die Untersuchung der Schmerzensbeschwerde aus der Perspektive psychoanalytischer Behandlung, aufgrund einiger freudschen Konzepte zur Behandlung von Schmerz. Ausgangspunkt ist die Erfahrungssammlung bei der Arbeit in einem psychiatrischen Krankenhaus, wobei die Behandlung von Patienten mit Schmerzensbeschwerden analysiert wird, um den Schmerz. im Rahmen der Psychoanalyse, im Unterschied zum medizinischen Rahmen, zu definieren und zu situieren. Im Text wird Schmerz als Äußerung von Leiden dargestellt, sowie aus verschiedenen Perspektiven beleuchtet und zwar, sowohl aus der Perspektive des Leidenden wie auch aus der Perspektive der Institutionen, die Schmerzensbehandlung anbieten.

Schlüsselwörter: Schmerz, Psychoanalyse, Kinderarzt, Leiden

Citação/Citation: Minatti, S. P. (2012, dezembro). O psicanalista no tratamento da dor. Revista Latinoamericana de Psicopatologia Fundamental, 15(4), 825-837.

Editor do artigo/Editor: Prof. Dr. Manoel Tosta Berlinck

Recebido/Received: 27.9.2011 / 9.27.2011 Aceito/Accepted: 23.11.2011/ 11.23.2011 


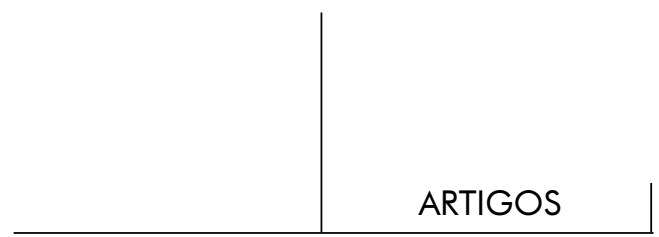

Copyright: (C) 2009 Associação Universitária de Pesquisa em Psicopatologia Fundamental/ University Association for Research in Fundamental Psychopathology. Este é um artigo de livre acesso, que permite uso irrestrito, distribuição e reprodução em qualquer meio, desde que o autor e a fonte sejam citados / This is an open-access article, which permits unrestricted use, distribution, and reproduction in any medium, provided the original author and source are credited.

Financiamento/Funding: A autora declara não ter sido financiada ou apoiada / The authors has no support or funding to report.

Conflito de interesses/Conflict of interest: A autora declara que não há conflito de interesses / The author declares that has no conflict of interest.

\section{Sueli Pinto Minatti}

Psicóloga; Psicanalista; Mestre em Psicologia Clínica pela Pontifícia Universidade Católica de São Paulo - PUC-SP (São Paulo, SP, Br); trabalhou no Instituto da Criança da Faculdade de Medicina de Universidade de São Paulo - FMUSP (São Paulo, SP, Br).

Rua Silvio Tramontano, 231 - casa 28

05692-050 São Paulo, SP

Fone: (11) 99655-0164

e-mail: minatti@uol.com.br 